\title{
Express method for evaluating the suitability of a polymer or composite of thereof for fused deposition modeling 3D printing
}

\author{
K.A. Kirshanov*, A.Yu. Gerval'd, R.V. Toms \\ FGBOU VO MIREA - Russian Technological University \\ 119571, Russia, Moscow, prosp. Vernadskogo, 86 \\ *E-mail: kirill_kirshanov@mail.ru
}

\begin{abstract}
The paper formulates requirements for a polymer material for molding products from it by fused deposition modeling. A methodology for evaluating the suitability of a polymer or composite of thereof in 3D printing technology has been developed. A graphic representation of the developed methodology in the form of a temperature-shear rate logarithm diagram is proposed. Application of the proposed methodology makes it possible to simplify the development of new materials for 3D printing by fused deposition modeling both at the stage of selecting the components of the polymer composition and at the stage of its subsequent approbation.
\end{abstract}

Keywords: polymer, polymer composite, 3D printing, FDM, fused deposition modeling, FFF, fused filament fabrication

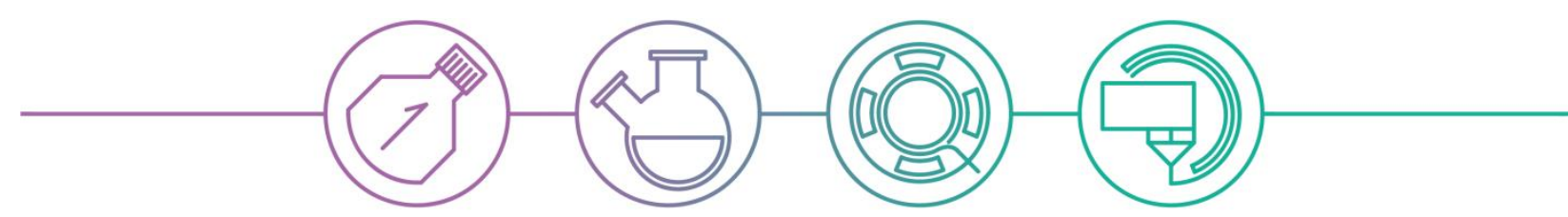

The newest way of molding products for various purposes from polymeric materials is $3 \mathrm{D}$ printing. Therefore, the development of $3 \mathrm{D}$ printing today is an urgent and promising task [1]. 3D printing technologies are used for rapid prototyping (making prototypes, models or shapes for different stages of production). In addition, 3D printing is also used for the rapid production of small batches of finished products, which usually have a unique shape. The popularity of 3D printing, among other things, is due to the relatively low flexibility of classical processing technologies. First of all, their flexibility is limited by the high cost and complexity of replacing the forming tools: injection molds, blow molds, and others. [2].

Currently, there are a large number of options for 3D printing technologies with polymer compositions. All these technologies involve creating a product model and dividing it into flat 
layers of a given thickness. On a 3D printer, the product is created by sequentially creating and attaching layers to each other $[3,4]$.

The most widespread among 3D printing technologies is the fused deposition modeling method (FDM), also called fused filament fabrication (FFF). The publication activity of researchers in the field of FDM (FFF) printing is shown in Figure 1.

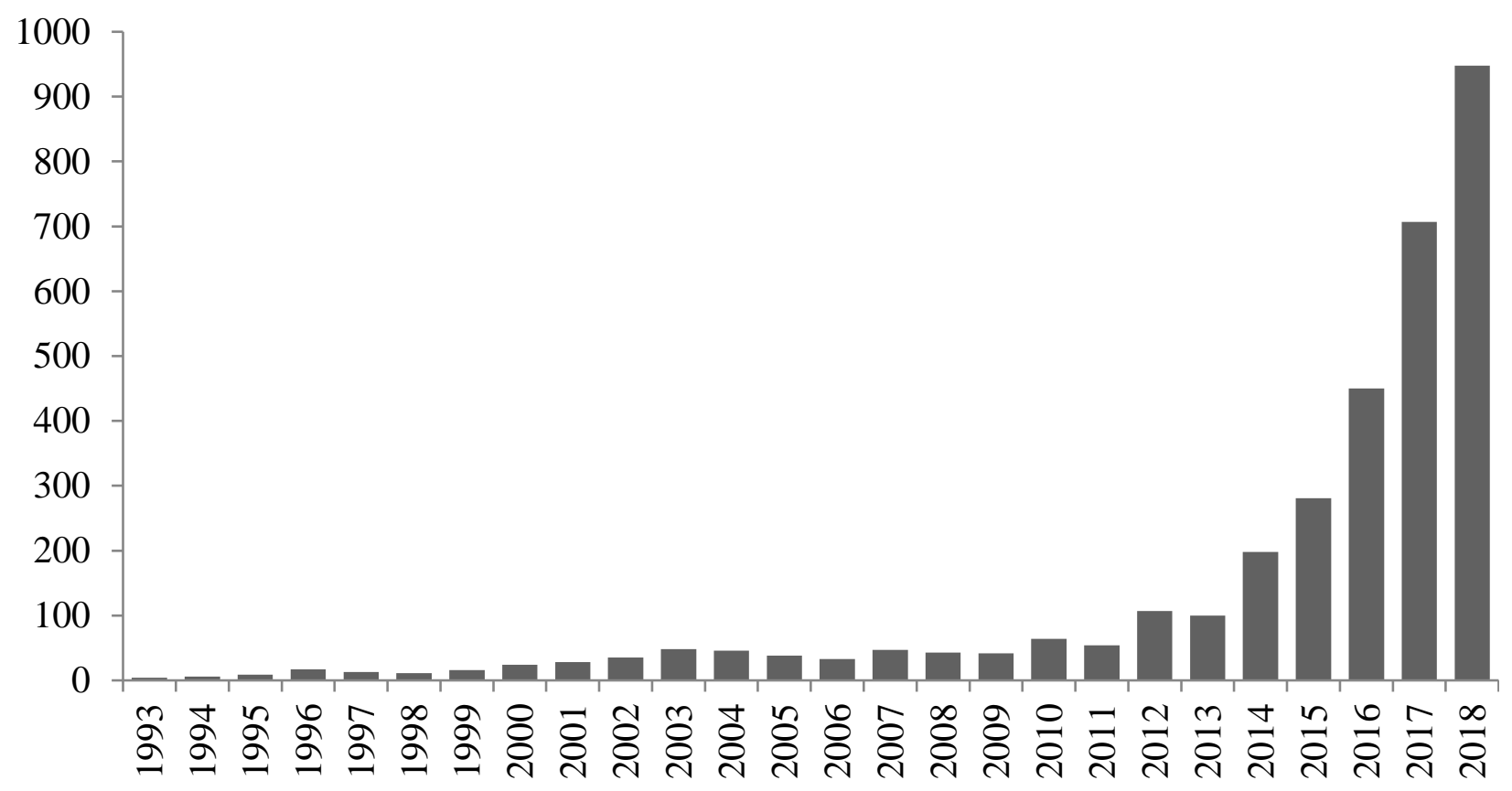

Fig. 1. Number of articles included in Scopus (scopus.com) that mention (title, abstract or keywords) FDM (FFF) technology, published in different years

At present, the structure of commercial FDM 3D printers [5] is optimal, and a subsequent qualitative change in equipment for this technology should not be expected. The further development of the 3D printing market is strongly limited by the shortcomings of printing materials. [6]. These disadvantages include the high cost of filament and the limited choice of materials. And if the problem of the high cost of filament can be solved by optimizing production stages and increasing production capacity, then in order to expand the range of materials for $3 \mathrm{D}$ printing, it is necessary to formulate requirements for such materials and conduct a qualitative and quantitative assessment of the degree of their application for 3D printing.

Thus, the purpose of the work is to develop an express method that will make it possible to reasonably choose a polymer material for $3 \mathrm{D}$ printing, check the printability and determine the intended working area of the material for further experiments on a $3 \mathrm{D}$ printer.

FDM 3D printing is based on the ability of a polymer material to form layers from a melt. This ability is largely due to the viscosity of the polymer material under processing conditions [7-9]. 
In plastics processing technology, the melt viscosity of a polymer material depends on the origin of the polymer (composition, average molecular weight and molecular weight distribution) and technological conditions (shear rate and processing temperature). The dependence of melt viscosity on shear rate at different temperatures is called polymer viscosity curves. The data that can be obtained from the viscosity curves form the working area of processing of the polymer material into the finished product. The boundaries of such an area are the ranges of temperatures and shear rates during processing.

However, on the one hand, there are a number of technological characteristics of the polymer material, which limits the area within which it can be processed. These characteristics are shrinkage and thermal stability. On the other hand, the working area of polymer processing is limited by the technical characteristics of 3D printers.

To apply the resulting working area to the FDM 3D printing process, it is necessary to correlate the characteristics of the printer, process and material with the values of temperatures and shear rates. The diagram of their connections is shown in the figure 2.

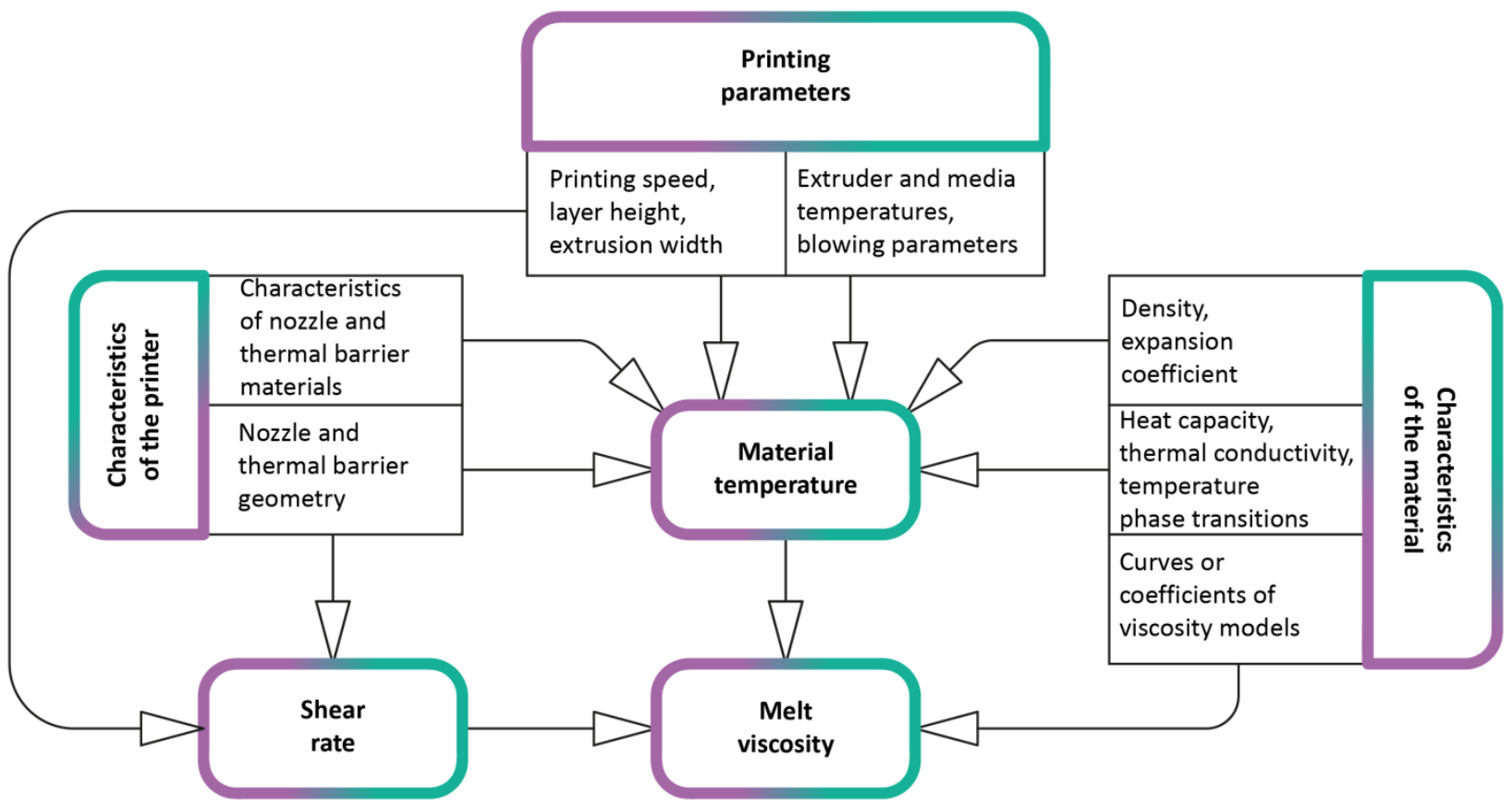

Fig. 2. Diagram of the influence of the characteristics of the printer, process and material on the shear rate, temperature and viscosity of the melt

In the case of fused deposition modeling, the shear rate depends on the nozzle diameter and the volumetric flow rate. Unlike extrusion, the volumetric flow rate is determined directly by the specified process parameters: extrusion width, layer thickness and print speed [10]. For an approximate description of a non-Newtonian fluid, it is most convenient to use the correction factor [11]. Thus, the formula for the shear rate will look like this (1):

$$
\dot{\gamma}=\frac{32 \mathrm{e}_{0} \times \mathrm{Q}}{\pi \mathrm{d}^{3}}=\frac{32 \mathrm{e}_{0} \times \mathrm{a} \times \mathrm{b} \times \mathrm{c}}{\pi \mathrm{d}^{3}}
$$


where $\dot{\gamma}$ is the shear rate, $\left[\mathrm{s}^{-1}\right], \mathrm{e}_{0}$ is the correction factor, $\mathrm{Q}$ is the volumetric flow rate, $\left[\mathrm{mm}^{3} \mathrm{~s}^{-1}\right], \mathrm{d}$ is the nozzle diameter, $[\mathrm{mm}], \mathrm{a}$ is the printing speed, $\left[\mathrm{mm} \mathrm{s}^{-1}\right], \mathrm{b}-$ extrusion width, $[\mathrm{mm}], \mathrm{s}$ - layer thickness, [mm].

In this case, the factor $\mathrm{e}_{0}$ can be taken equal to 0.815 [11]. The extrusion width is usually equal to the nozzle diameter.

The temperature depends on the supply and removal of heat, which is influenced by the thickness and characteristics of the materials of the walls of the nozzle and thermal barrier, the temperature of the circulating air (room temperature in printers without a chamber, higher in printers with a chamber), and the temperature of the extruder. Also, the temperature profile determines the thermal conductivity and heat capacity of the polymer material, the characteristics of phase transitions $[12,13]$. The exact value of the temperature can be found by mathematical modeling, but the extruder temperature can be used with acceptable accuracy.

It is also necessary to achieve sufficient bond strength, which increases in proportion to the temperature, and therefore there is a minimum allowable temperature value $[14,15]$. Finally, in order to achieve the maximum surface tension, which will provide a sufficient contact area with the previous layer, it is necessary to reach a certain minimum temperature value [15]. However, at temperatures at which the material passes into a viscous-flowing state, it is almost always possible to achieve sufficient strength of the welded joint [16], which is close to the joint between the layers of the product during printing, also the surface tension will be sufficient. For this reason, although these indicators are important for predicting bond strength and the entire product [17], it is not necessary to take them into account when assessing the suitability of a polymer or composition for fused deposition modeling. We also believe that under the processing mode in commercial FDM 3D printers, values of the shear rate close to the critical value are not achieved.

Thus, the method for choosing a polymer material for 3D printing is based on the idea of constructing a working area for processing a polymer material, which, in turn, is the intersection of the sets of allowable temperatures and shear rates according to various criteria: the viscosity range, the capabilities of commercial printers, shrinkage and thermal stability.

Further, the influence of each of the criteria on the formation of the area of processing of polymeric material by the FDM 3D printing is considered.

According to the literature, the working range of viscosities of the polymer melt for forming a layer (at the exit from the nozzle) is from 80 to $2000[\mathrm{~Pa} \mathrm{~s}]$, or from 1,9 to $3,3[\lg (\mathrm{Pa}$ s)] in logarithmic coordinates [8]. To determine the values of shear rates and temperatures, it is convenient to use the viscosity curves [7-9]. Typical viscosity curves for a polymer melt are shown in Figure 3. 


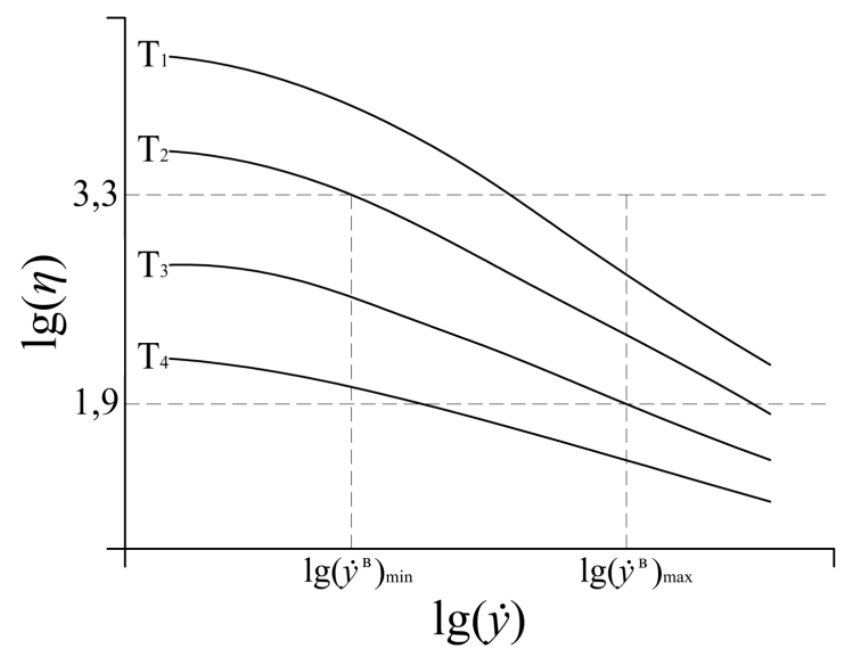

Fig. 3. Typical form of viscosity curves for thermoplastic in logarithmic coordinates

From the viscosity curves, it is necessary to choose such temperatures and shear rates at which the logarithm of the viscosity will decrease linearly. Also, the range should be wide enough so that, depending on the purpose of printing, the viscosity can be varied over a wide range. For example, in Figure 3, the maximum value of the logarithm of viscosity 3,3 $[\lg (\mathrm{Pa} \mathrm{s})]$ corresponds to the point with the minimum shear rate $\lg \left(\dot{\gamma}^{\mathrm{B}}\right)_{\min }$ and the minimum temperature $\mathrm{T}_{2}$, nd the minimum value of the logarithm of viscosity $1,9[\lg (\mathrm{Pa} \mathrm{s})]-$ a point with a maximum shear rate $\lg \left(\dot{\gamma}^{\mathrm{B}}\right)_{\max }$ and a maximum temperature $\mathrm{T}_{3}$. Therefore, when printing, it is permissible to use any pair of values of the logarithms of shear rates in the range from $\lg \left(\dot{\gamma}^{\mathrm{B}}\right)_{\min }$ to $\lg \left(\dot{\gamma}^{\mathrm{B}}\right)_{\max }$ and temperatures from $\mathrm{T}_{2}$ to $\mathrm{T}_{3}$.

There are minimum and maximum temperature and shear rates within which commercial printers can operate. The printer may maintain unstable values outside these intervals or not reach them at all.

To determine temperatures and shear rates, we analyzed data on minimum and maximum extruder temperatures, minimum and maximum print speeds, minimum layer thicknesses and available nozzle radii for 49 brands of commercial FDM 3D printers available on the market.

The minimum boundaries of the temperature range are due to the inability to maintain a stable value, and not all printers have them. The maximum temperature is limited by the power of the printer, its construction and materials. The number of printers with different minimum and maximum temperatures is shown in Figure 4. 


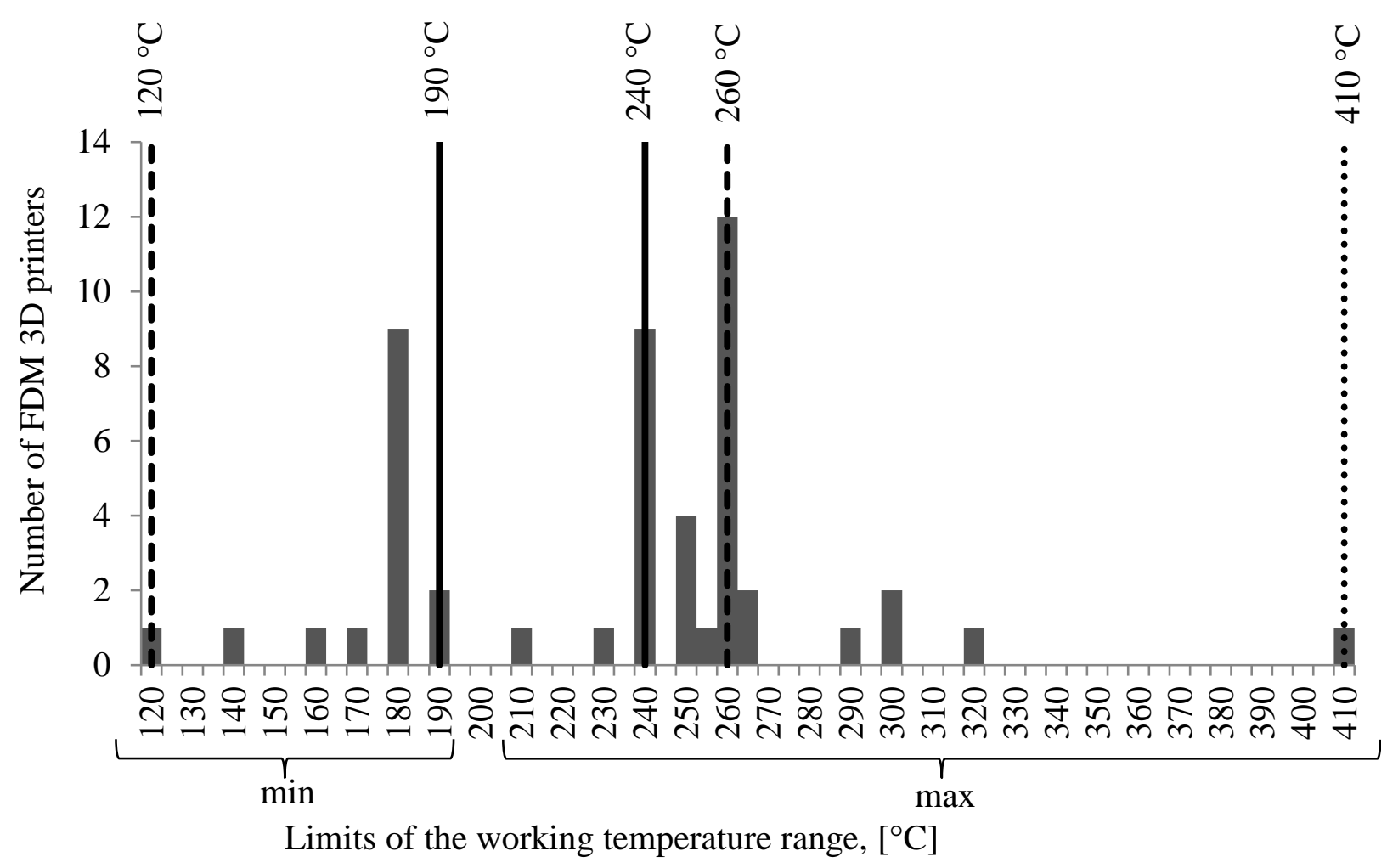

Fig. 4. Number of FDM 3D printers by minimum and maximum printing temperatures, a sample of 49 commercial printers

Material made for use in simple consumer printers should be suitable for most printers. Its working area should be between 190 and $240\left[{ }^{\circ} \mathrm{C}\right]$. For material that is intended for industrial processing, this interval can be wider, since more powerful and reliable printers are used. The working area should be in the range from 120 to $260\left[{ }^{\circ} \mathrm{C}\right]$, in rare cases the maximum processing temperature can reach up to $410\left[{ }^{\circ} \mathrm{C}\right]$.

Shear rates are found from Equation (1) using shear rates, layer thicknesses, and nozzle diameters for a sample of commercial fused-layer printers. The number of printers with different minimum and maximum temperatures is shown in Figure 5. 


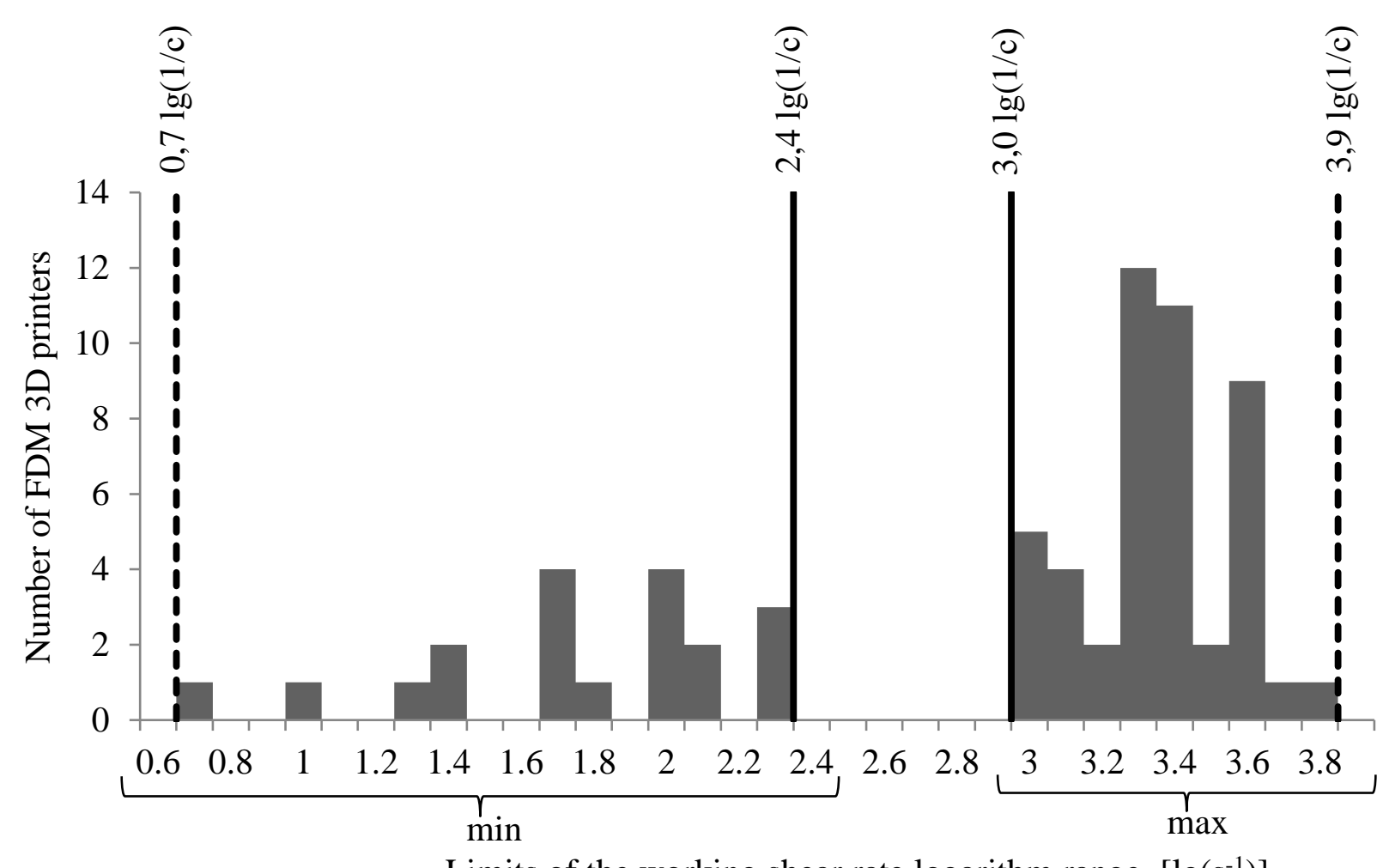

Fig. 5. Number of FDM 3D printers by minimum and maximum shear rates, a sample of 49 commercial printers

The boundaries of the intervals were chosen according to the same principle as in the case of temperatures. For use in consumer printers, the working area of the material should lie in the range from 2.4 to $3.0\left[\mathrm{~s}^{-1}\right]$, for industrial use it can lie in the range from 0.9 to $3.9\left[\mathrm{~s}^{-1}\right]$.

In fused deposition modeling it is necessary that the shrinkage is minimal, that is, has the maximum allowable value determined by the maximum temperature value $[7,8]$.

Low and isotropic shrinkage ensures that the product remains as close to the designed shape as possible and does not delaminate. For shrinkage, the design of the printer is of paramount importance. For a printer without a closed print chamber, the shrinkage for each layer will occur immediately to a value corresponding to the temperature of the medium. For a printer with a closed print chamber, the shrinkage of each layer occurs to a value corresponding to the temperature inside the closed print chamber, and after removing the finished product, an additional uniform shrinkage of the entire product at once to a value corresponding to the temperature of the medium occurs, which prevents delamination. Currently, for printing on printers without a closed print chamber, materials with a shrinkage of up to $0.5 \%$ at processing temperatures are used, on printers with a closed print chamber - up to $1.5 \%$. It is possible to determine the maximum operating temperature by the shrinkage parameter using the shrinkage versus time dependences, which are shown in Figure 6. 


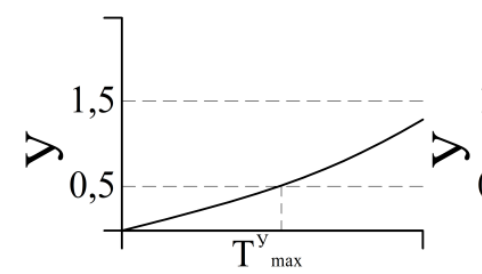

$\mathrm{T}$

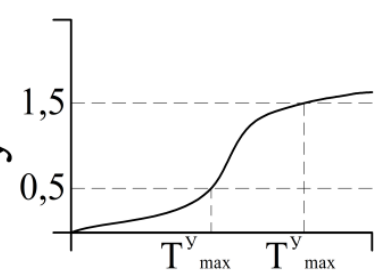

$\mathrm{T}$

Fig. 6. Typical form of dependences of shrinkage on the temperature at which shrinkage occurs to the temperature of the medium, for amorphous (left) and partially crystalline (right) thermoplastics

For polymers that are amorphous under processing conditions, the dependence of shrinkage on temperature will be more linear and much less pronounced, therefore they are usually used in printing. It is also noteworthy that due to the absence of supramolecular crystalline formations, the interdiffusion of segments of macromolecules occurs more easily, which also increases the strength of the connection. If the polymer crystallizes under processing conditions, then it is characterized by large shrinkage, often with high anisotropy. It is possible to reduce the crystallinity of the polymer by changing the printing conditions: for example, increasing the flow of circulating air, which will accelerate the cooling to the ambient temperature. Also, unwanted crystalline areas can occur if the shape of the product is not taken into account. Then, if a new layer is laid before the previous one has completely cooled, its cooling will be slowed down, and partial crystallization will have time to occur.

In order for the polymer to be sufficiently thermally stable during processing by the FDM $3 \mathrm{D}$ printing method, both the maximum limitation on the processing temperature and the maximum limitation on the residence time corresponding to the minimum value of the shear rate are necessary $[7,8]$.

To find the boundary value of the temperature and shear rates for thermal stability [7,8], it is necessary to use several curves of thermal stability at different temperatures, which should be used to determine the times of thermal stability at different temperatures, which is shown in Figure 7.

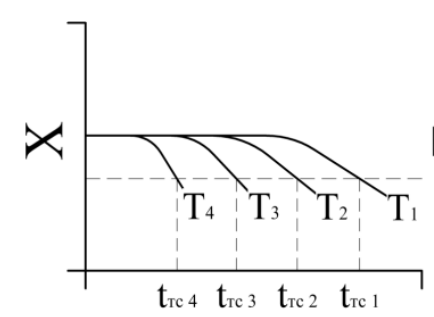

$t$

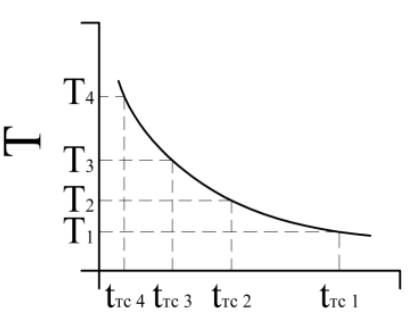

$t_{\mathrm{Tc}}$

Fig. 7. Typical view of thermal stability curves at different temperatures (left) and temperaturethermal stability diagram (right) 
The thermal stability time can be converted into the minimum shear rate to construct the working range of temperatures and shear rates in thermal stability as follows. At the beginning, it is necessary to find the time $t_{p}[s]$, at which, with a residence time equal to the thermal stability time, it is the extrusion of the melt from the nozzle that occurs, according to the following formula (2):

$$
t_{p}=t_{t s} / X
$$

where $t_{t s}$ is the thermal stability time, $[\mathrm{s}], \mathrm{X}$ is the correction factor. The correction factor takes into account the time of auxiliary operations - transfer of the extruder between different points, the transition between layers, additional cooling of the layer. It depends on the shape of the product, the number of layers and the thickness of each layer, the blowing time of each layer, the printing speed, the transfer speed of the extruder and many other parameters. $\mathrm{X}$ will always be greater than 1. $\mathrm{X}$ for a specific product can also be calculated using the formula (2), having determined $t_{p}$, knowing the volume of material used to create the product, and the volumetric flow rate from formula (1), and for $t_{t c}$, taking the printing time proposed by the slicer based on the selected parameters of the printing process. When choosing the $\mathrm{X}$ value for the design task, the Ultimaker Cura 4.7.1 and Createbot 3D Software slicers were used, X was determined for products for various purposes when changing the print parameters in a wide range. It was found that $\mathrm{X}$ will almost always lie in the range from 1 to 3; therefore, for the material under study, it is sufficient to take the correction factor equal to 3 . In fact, this means that only one third of the time the material is in the nozzle will be extruded, in the other two thirds of the time it will be blowing, moving the printing unit or table and other processes. When developing materials for rapid prototyping, which involves a large number of thin layers and careful cooling, a higher $\mathrm{X}$ value should be used.

After that, the volumetric flow rate Q can be determined by the formula (3):

$$
\mathrm{Q}=\mathrm{V}_{\mathrm{c}} / \mathrm{t}_{p}
$$

where $\mathrm{V}_{\mathrm{c}}$ is the volume of the nozzle, $\left[\mathrm{mm}^{3}\right]$. The volume of a conventional nozzle is a little over $30\left[\mathrm{~mm}^{3}\right]$.

Thereafter, the shear rate can be found from formula (1) from the known nozzle diameter and the calculated volumetric flow rate. From the found points, the temperature-shear rate logarithm can be used to construct the maximum thermal stability curve $\left(\mathrm{T}^{\mathrm{T}}-\lg \left(\dot{\gamma}^{\mathrm{T}}\right)\right.$ curve $)$.

Thus, sets of admissible values of temperature and shear rate were obtained according to criteria such as the viscosity range (from $\lg \left(\dot{\gamma}^{\mathrm{B}}\right)_{\min }$ to $\lg \left(\dot{\gamma}^{\mathrm{B}}\right)_{\max }$, from $\mathrm{T}^{\mathrm{B}}{ }_{\min }$ to $\mathrm{T}^{\mathrm{B}}{ }_{\text {max }}$ ), technical capabilities of commercial printers (from $\lg \left(\dot{\gamma}^{\Pi}\right)_{\min }$ to $\lg \left(\dot{\gamma}^{\Pi}\right)_{\max }$, from $\mathrm{T}^{\Pi}{ }_{\min }$ to $\mathrm{T}^{\mathrm{\Pi}}{ }_{\max }$ ), shrinkage (up to $\mathrm{T}_{\text {max }}^{\mathrm{y}}$ ) and thermal stability $\left(\mathrm{T}^{\mathrm{T}}-\lg \left(\dot{\gamma}^{\mathrm{T}}\right)\right.$ curve). Having constructed graphically the 
intersection of all the listed sets, in the area of their intersection, it is possible to obtain a working area for printing with a polymer material, as shown in Figure 8.

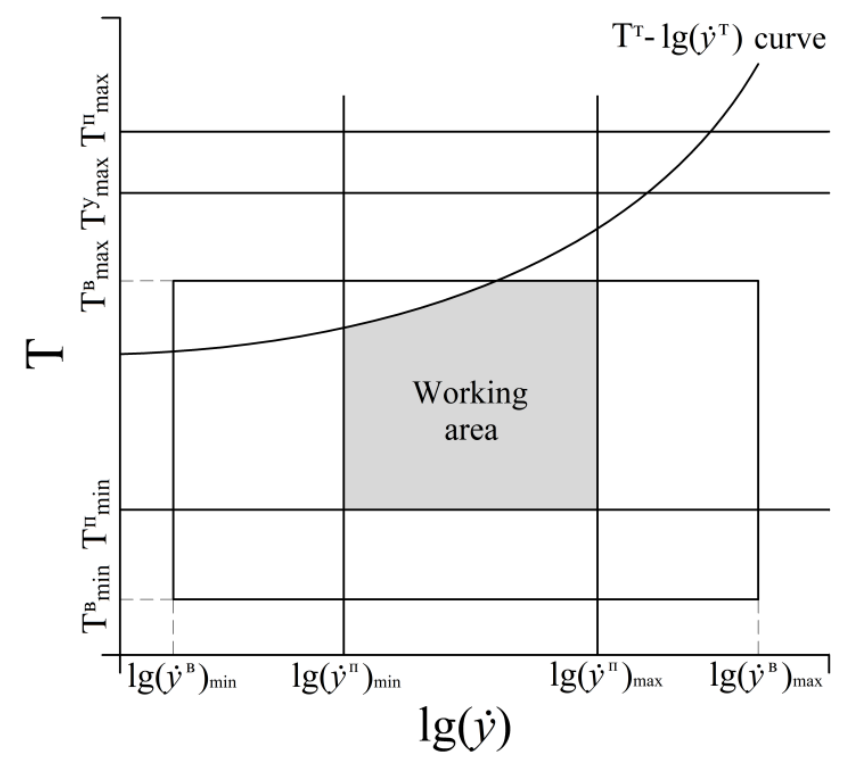

Fig. 8. Typical view of the working area on the temperature-shear rate logarithm diagram

To be successful in printing, the work area must be wide enough both in temperature and in the logarithm of the shear rate. If there is no such area, then printing with such a polymer is impossible. For most polymeric materials, high shrinkage is the reason for the inability to print.

When constructing a similar diagram for a polymer, it is possible to evaluate which additives are necessary to expand the working area. It is worth noting that the introduction of filler in fused deposition modeling can lead to rapid wear of the nozzle on an ordinary consumer printer. The most important additive for FDM 3D printing compositions is a plasticizer, since it both reduces the viscosity, allowing the use of lower processing temperatures, and increases the strength of the "welded" joint between layers [16].

To test the performance of the model, we used materials already studied in other sources $[10,18]$. The values of the intervals of the shear rates logarithms and temperatures proposed by the manufacturer for printing, obtained empirically when printing with material of the same brand and working areas obtained on the diagrams that are proposed in this work, are compared. Experimental data were obtained by visual assessment for the presence of defects when printing with various combinations of temperatures and printing speeds, so it is worth considering the human factor and their possible inaccuracy. Print speeds are converted to log shear rates using formula (1) using a layer thickness of $0.1[\mathrm{~mm}]$ and a nozzle diameter of $0.4[\mathrm{~mm}]$. The results are shown in Table 1.

Table 1. Comparison of temperature ranges and logarithms of shear rates for different materials proposed by the manufacturer, obtained experimentally and theoretically 


\begin{tabular}{|c|c|c|c|c|c|c|}
\hline \multirow{2}{*}{$\begin{array}{l}\text { Material and its } \\
\text { properties }\end{array}$} & \multicolumn{2}{|c|}{$\begin{array}{l}\text { Manufacturer's } \\
\text { recommendations }\end{array}$} & \multicolumn{2}{|c|}{ Experimental definition } & \multicolumn{2}{|c|}{$\begin{array}{l}\text { Forecast for the } \\
\text { proposed model }\end{array}$} \\
\hline & $\begin{array}{l}\lg (\dot{\gamma}), \\
{[\lg (\text { Pa s })]}\end{array}$ & $\mathrm{T},\left[{ }^{\circ} \mathrm{C}\right]$ & $\begin{array}{l}\lg (\dot{\gamma}) \\
{[\lg (\mathrm{Pa} \mathrm{s})]}\end{array}$ & $\mathrm{T},\left[{ }^{\circ} \mathrm{C}\right]$ & $\begin{array}{l}\lg (\dot{\gamma}) \\
{[\lg (\text { Pa s })]}\end{array}$ & $\mathrm{T},\left[{ }^{\circ} \mathrm{C}\right]$ \\
\hline $\begin{array}{l}\text { HIPS natural } \\
\text { (eSun) }\end{array}$ & $\begin{array}{l}\text { From } 2,2 \\
\text { to } 2,6\end{array}$ & $\begin{array}{l}\text { From } 220 \\
\text { to } 260\end{array}$ & $\begin{array}{l}\text { From } 1,7 \\
\text { to } 2,7\end{array}$ & $\begin{array}{l}\text { From } 230 \\
\text { to } 260\end{array}$ & $\begin{array}{l}\text { From } 1,5 \\
\text { to } 3,0\end{array}$ & $\begin{array}{l}\text { From } 215 \\
\text { to } 275\end{array}$ \\
\hline $\begin{array}{l}\text { PC Transparent } \\
\text { (Ultimaker) }\end{array}$ & - & $\begin{array}{l}\text { From } 260 \\
\text { to } 280\end{array}$ & $\begin{array}{l}\text { From } 1,7 \\
\text { to } 2,4\end{array}$ & $\begin{array}{l}\text { From } 255 \\
\text { to } 275\end{array}$ & Up to 3,0 & $\begin{array}{l}\text { From } 240 \\
\text { to } 285\end{array}$ \\
\hline $\begin{array}{l}\text { Nylon } 618 \\
\text { (Taulman 3D) }\end{array}$ & $\begin{array}{l}\text { From } 2,1 \\
\text { to } 2,3\end{array}$ & $\begin{array}{l}\text { From } 240 \\
\text { to } 265\end{array}$ & $\begin{array}{l}\text { From } 1,7 \\
\text { to } 2,3\end{array}$ & $\begin{array}{l}\text { From } 225 \\
\text { to } 280\end{array}$ & $\begin{array}{l}\text { From } 1,8 \\
\text { to } 3,0\end{array}$ & $\begin{array}{l}\text { From } 230 \\
\text { to } 280\end{array}$ \\
\hline
\end{tabular}

The proposed assessment method demonstrates sufficient accuracy. It can be seen that the manufacturer's recommendations in all considered cases lie within the interval obtained from the temperature-shear rate logarithm diagram.

Thus, it was shown that the ability of FDM 3D printing mainly depends on temperature and logarithm of shear rate. Calculation of the shear rate for this process is proposed. Limitations of temperature and logarithm of shear rate are highlighted by the following parameters: viscosity, thermal stability, shrinkage. The limitations on temperatures and logarithms of shear rates of commercial printers on the market are estimated. A method is proposed for assessing the suitability of a polymer or polymer composition for fused deposition modeling, based on the use of viscosity curves, the dependence of shrinkage on temperature, and thermal stability curves. The method is applied graphically in the form of a temperature-shear rate logarithm diagram, its construction is shown. The necessity of using amorphous polymers under processing conditions is suggested.

\section{References}

1. Gibson I., Rosen D.W., Stucker B. Additive Manufacturing Technologies. Rapid Prototyping to Direct Digital Manufacturing. - Springer, 2010. - 473 p.

2. Mymrin V.N. Sovremennaya industriya plastmass: rynok i ekonomika, tekhnologii i tendencii. Okonchanie // Polimernye materialy. - 2019. - № 5. - S. 4-9. (In Russ).

3. Litunov S.N., Slobodenyuk V.S., Mel'nikov D.V. Obzor i analiz additivnyh tekhnologij. CHast' 1 // Omskij nauchnyj vestnik. - 2016. - № 1 (145). - S. 12-17. (In Russ).

4. Litunov S.N., Slobodenyuk V.S., Mel'nikov D.V., Fedyanin V.V., Koshcheeva N.S. Obzor i analiz additivnyh tekhnologij. CHast' 2 // Omskij nauchnyj vestnik. - 2016. - № 5 (149). - S. 2024. (In Russ).

5. Pat. 5121329 USA, IPC G06F 15/46. Apparatus and method for creating three-dimensional objects / S.S. Crump. - № 429012; declared 30.09.1989; published 09.06.1992. - 15 p. 
6. Tokarev B.E. Rynok 3D-pechati: drajvery i bar'ery // Prakticheskij marketing. - 2014. - № 4 (206). - S. 3-9. (In Russ).

7. Petrova G.N., Platonov M.M., Bol'shakov V.A., Ponomarenko S.A. Research of the complex of characteristics of base materials for FDM of technology of the additive synthesis. Physicomechanical and heat-physical properties // Plasticheskie massy. - 2016. - № 5-6. - S. 53-58. (In Russ).

8. Petrova G.N., Sapego Yu.A., Larionov S.A., Platonov M.M., Laptev A.B. Pozharobezopasnye termoplastichnye materialy dlya 3D-tekhnologii // Trudy VIAM. - 2017. - № 9 (57). - S. 56-65. (In Russ).

9. Gonzalez-Henriquez C.M., Sarabia-Vallejos M.A., Rodriguez-Hernandez J. Polymers for additive manufacturing and 4D-printing: materials, methodologies, and biomedical applications // Progress in polymer science. - 2019. - V. 94. - P. 57-116.

10. Coogan T.J., Kazmer D.O. In-line rheological monitoring of fused deposition modeling // Journal of Rheology. - 2019. - V. 63. - I. 1. - P. 141-155.

11. Mikaeli V. Ekstruzionnye golovki dlya plastmass i reziny: Konstrukcii i tekhnicheskie raschyoty / Per. s angl. yaz.; Pod red. V.P. Volodina. - SPb.: Professiya, 2007. - 472 s. (In Russ).

12. Yong Zhou, Gang Xiong, Timo Nyberg, Dan Liu Temperature analysis in the fused deposition modeling process // Proceedings of the 3rd International Conference on Information Science and Control Engineering, 8.07.2016-10.07.2016. - Beijing, China, 2016. - P. 678-682.

13. Rahman M., Schott N. R., Sadhu L.K. Glass Transition of ABS in 3D Printing // Proceedings of the COMSOL Conference, 13.10.2016. - Boston, USA, 2016. - P. 1-5.

14. Sun Q., Rizvi G.M., Bellehumeur C.T., Gu P. Effect of processing conditions on the bonding quality of FDM polymer filaments. // Rapid Prototyping Journal. - 2008. - V. 14. - I. 2. - P. $72-$ 80 .

15. Coogan T.J., Kazmer D.O. Modeling of interlayer contact and contact pressure during fused filament fabrication // Journal of Rheology. - V. 63. - I. 4. - P. 655-672.

16. Zajcev K.I., Macyuk L.N. Svarka polimernyh materialov: Spravochnik. - M.: Mashinostroenie, 1988. - 312 s. (In Russ).

17. Garzon-Hernandeza S., Garcia-Gonzaleza D., Jerusalemb A., Arias A. Design of FDM 3D printed polymers: An experimental-modelling methodology for the prediction of mechanical properties // Materials and Design. - 2020. - V. 118. - P. 108414.

18. Petrova G.N., Larionov S.A., Sorokin A.E., Sapego Yu.A. Sovremennye sposoby pererabotki termoplastov // Trudy VIAM. - 2017. - № 17 (59). - S.56-72. (In Russ). 